\title{
CLINICAL AND RADIOGRAPHIC OUTCOMES OF IMMEDIATELY LOADED IMPLANTS FOLLOWING ALVEOLAR RIDGE PRESERVATION UTILIZING BIOSCAFFOLD
}

\author{
Lydia N. Melek* and Mohamed M. Shokry*
}

\begin{abstract}
Background: Preservation of socket at the time of tooth extraction is driven by the desire to minimize the need for future more invasive ridge augmentation procedures. Moreover, it also facilitates successful implant and conventional prosthetic treatment.
\end{abstract}

Purpose: the aim of this study was to evaluate the use of Alvelac ${ }^{\mathrm{TM}}$ as a bioscaffold for socket preservation with subsequent placement of immediately loaded dental implants

Materials and methods: This study was carried out as a randomized controlled clinical trial. Twenty patients, in need for extraction of a non-restorable posterior maxillary tooth were selected from those attending the outpatient clinic of Oral and Maxillofacial Surgery Department, Faculty of Dentistry, Alexandria University. After selection of the sample conveniently, it was randomly allocated into two equal groups each consisted of ten participants. The study group; in which the maxillary teeth were extracted and the bioscaffold Alvelac ${ }^{\mathrm{TM}}$ was inserted into the empty socket and supported by 3-0 black silk with a figure of eight sutures. Three months later, immediately loaded dental implants were inserted. Whereas in the control group; the extraction of teeth was done without introducing any material and the wound was closed and supported by 3-0 silk with a figure of eight sutures. Then three months later, immediately loaded dental implants were inserted

Results: As for alveolar bone width and height, the current work reveals statistically significant difference between the two groups, regarding the percent of change three months post-extraction and at the time the implants were inserted. A statistically significant difference was found in bone density between the two groups, immediately post-operative and at the first month after implant insertion. However, at the time of three and six months after implants were inserted, there was no statistically significant difference between the two groups.

Conclusions: insertion of the bioscaffold Alvelac ${ }^{\mathrm{TM}}$ material in the socket immediately after tooth extraction allows it to act as a scaffold for bone deposition and it assists the natural healing process. Furthermore, treating the socket with Bioscaffold results in natural healing within the given time frame with better bone quality. It is clear that this material allows preservation of the dimensional measures of alveolar bone after tooth extraction. Finally, the material is believed to assist in increasing the success rate of the immediately loaded dental implants.

\footnotetext{
* Lecturer of Oral and Maxillofacial Surgery, Faculty of Dentistry, Alexandria University.
} 


\section{INTRODUCTION}

Dentistry has entered an era in which patients no longer need to accept a tooth to be dismissed because of insufficient alveolar bone volume, height, or width. ${ }^{(1)}$ The aim of implant dentistry treatment is to restore the function of lost teeth. For satisfactory function and esthetics as well as for a predictable long-term treatment outcome,implants should be anchored in bone.(2)

As periodontal disease and tooth extractions cause atrophy and a narrowing of the residual alveolar ridge, implant sites may be impaired. ${ }^{(3)}$ Moreover, Mecall and Rosenfeld (1991) $)^{(4)}$ concluded that tooth extraction, either traumatic or atraumatic, results in alveolar bone loss, both in width and height.

Likewise, according to Sevor and Meffert $(1992)^{(5)}$, Grunder et al. (1999) ${ }^{(6)}$ an average of $40 \%$ to $60 \%$ of original height and width is expected to be lost after tooth extraction, with the greatest loss happening within the first year.This can negatively influence bone volume that is needed for future dental implant placement as well as proper ideal esthetic restoration.

Furthermore, the morphology of the alveolus is very much tooth dependent in that the development of alveolar bone is determined by the form of the teeth and the axis of tooth eruption. ${ }^{(7)}$ Consequently, it is not surprising that the alveolar process undergoes various degrees of atrophy when a tooth is removed in adulthood. Thus, the bone volume in the maxillary and mandibular alveolar ridges in buccolingual and apicocoronal directions influences a variety of factors related to oral health and potential restorative treatment, including the location and position of implants when placed, their subsequent success or failure, and the esthetics of the definitive restorations. ${ }^{(8)}$

For the aforementioned reasons, the dental team faces the formidable challenge of creating a prosthetic restoration that is indistinguishable from the surrounding natural dentition following tooth extraction. The concept of site preservation after tooth extraction is essential because of the normal resorptive process of the healed ridge..$^{(9)}$

So, in cases of alveolar resorption following tooth extraction, regeneration of bone by the aid of membrane and a bone graft substitute before or subsequent to implantation is of paramount importance, this will actually leads to broadening the number of appropriate implant sites..$^{(3,10)}$

Preservation of socket at time of tooth extraction is driven by the desire to minimize the need for future more invasive ridge augmentation procedures. Moreover, it also facilitates successful implant and conventional prosthetic treatment. Extraction site grafting often facilitates the best possible functional and aesthetic results. It is axiomatic therefore that socket preservation should be the treatment of choice to prepare the remaining alveolar ridge for conventional or fixture supported restorations..$^{(9,10)}$

The utilization of autologous bone graft for socket preservation is considered to be the gold standard due to its osteoinductive properties. However, harvesting autologous bone often requires additional surgical intervention and potential donor-site morbidity, and the quantity of sufficient autologous bone may necessitate extra-oral harvesting. This has led to the development of alternative bone graft materials in regenerative therapies such as allografts, xenografts, and synthetic calcium minerals and polylactic-coglycolic acid (PLGA). ${ }^{(1)}$

Alvelac $^{\mathrm{TM}}$ is a porous, osteoconductive, biocompatible and biodegradable synthetic scaffold that is synthesized from polylactic-co-glycolic acid (PLGA) and polyvinyl alcohol. It acts as a mechanical support to hold the blood clot after extraction at the crestal level of the socket. It also has the advantage of being capable of delivering drugs, proteins and growth factors to enhance bone healing in both oral-maxillofacial and general orthopedic applications. These characteristics not only increase cell proliferation in vitro, but provide a safe and osteoconductive environment for bone regeneration in vivo..$^{(12)}$ 
In light of the above information, the aim of this study was to evaluate the use of Alvelac ${ }^{\mathrm{TM}}$ as a bioscaffold for socket preservation with subsequent placement of immediately loaded dental implants.

\section{MATERIAL AND METHODS}

This study was carried out as a randomized controlled clinical trial. Twenty patients, in need for extraction of a non-restorable posterior maxillary tooth were selected from those attending the outpatient clinic of Oral and Maxillofacial Surgery Department, Faculty of Dentistry, Alexandria University. An informed consent was taken and signed after explanation to every patient the steps of the procedure performed.

The participants included within this study were selected to be free from any relevant diseases that may affect implantation, their age ranged between 25 - 45 years old, of both genders, and with good oral hygiene. On the other hand, exclusion was done for patients when the tooth indicated for extraction was acutely infected. Also, heavy smokers, patients suffering from bone disease as osteoporosis, and patients with uncontrolled diabetes were excluded from this study.

After selection of the sample conveniently, it was randomly allocated into two equal groups each consisted of ten participants.

- The study group;in which the maxillary teeth were extracted and the bioscaffold Alvelac ${ }^{\mathrm{TM}}$ (Bio Scaffold International BSI, Singapore)was inserted into the empty socket and supported by 3-0 black silk with a figure of eight sutures. Three months later, immediately loaded dental implants were inserted.

- Whereas in the control group;the extraction of teeth was done without introducing any material and the wound was closed and supported by 3-0 silk with a figure of eight sutures. Then three months later, immediately loaded dental implants were inserted.

\section{Pre-operative phase}

A detailed medical history was taken for all patients, followed by examination of the tooth needed for extraction both clinically and radiographically.

\section{Operative phase}

All procedures were performed under local anesthesia using $1.8 \mathrm{ml}$ mepivacaine HCL 2\% (Alexandria Co. for pharmaceuticals, Alexandria, Egypt) for infiltration of the superior alveolar nerve and the greater palatine nerve respectively. Extraction of teeth was performed in atraumatic method using curved periotomes (Hu-Friedy) followed by the appropriate maxillary forceps according to the tooth to be extracted. After tooth extraction, the socket was debrided using $0.9 \%$ normal saline solution.

For the study group; Alvelac ${ }^{\mathrm{TM}}$ was inserted within the socket according to the manufacturer's instructions. It is a rigid structure specifically designed to prevent collapse of the buccal and palatal walls to maintain ridge width. It is strategically placed in the extraction socket with the top of the scaffold in line with the crest of the socket in order to raise the forming blood clot to that level thus achieving height maintenance. The size of Alvelac ${ }^{\mathrm{TM}}$ does not occupy the whole socket thus allowing maximum space for blood to fill the socket. This allows for the patient's own bone to form naturally within that space by the action of Alvelac $^{\mathrm{TM}}$ as a bioscaffold (Figure 1). While, in the control group, the socket was left empty without placing any material.

\section{Follow-up phase}

All patients within the two groups were examined clinically for infection and healing for the first month following the extraction. They were also examined radiographically through a Cone Beam Computed Tomography (CBCT) (KODAK CS 3D Imaging)immediately postoperatively, serving as a baseline for later measurements and after 3 months 


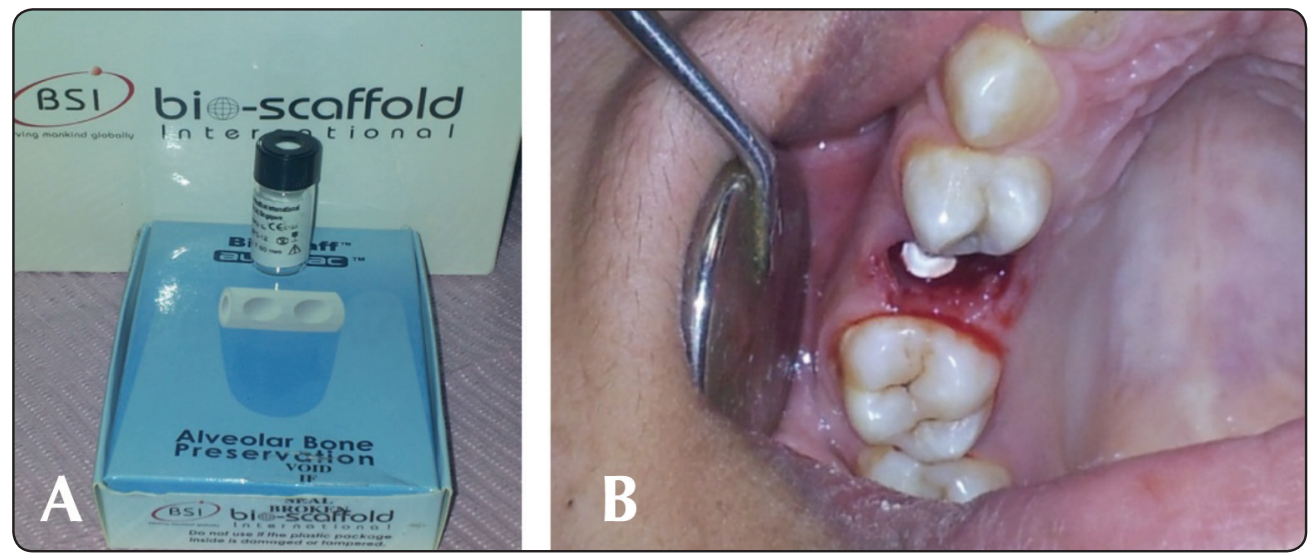

Fig. (1A): Alvelac Bioscaffold, (1B) Placement of Alvelac in the empty socket after extraction

of the extraction. The radiographic examination was done to assess bone height, bone width and bone density of the extracted sockets by the aid of a special software (On Demand 3DAPP-DBM).

After a period of three months, the patients of both groups were returned back to install a dental implant within the extracted socket (Dio dental implant;Korea). After proper treatment planning of the cases for the selection of the proper size of implants, a total of 20 implants were placed; 10 within the study group in which the sockets were preserved utilizing Alvelac ${ }^{\mathrm{TM}}$ and the other 10 implants were placed in the control group in which the sockets were left empty.

\section{Implant insertion:}

The surgical field was cleaned with a tincture iodine swab, then infiltration anesthesia was injected in the surgical site followed by reflection of a full thickness envelope flap in the proposed implant site. The osteotomy was prepared by drilling using pilot drill followed by the successive drills till reaching the final drill which corresponds to $0.5 \mathrm{~mm}$ less than the diameter of the selected implant. Drilling was made under copious external irrigation by normal saline as cooling system, depth of the drilling was monitored using depth gauge, and parallelism was checked using paralleling pins. After drilling and debridement, the implant was held by its cover and inserted into the osteotomy site.

Immediate loading with ready-made acrylic crowns (Provyl, Dentsply®, USA) which were adjusted to be $2 \mathrm{~mm}$ free from occlusion in centric and eccentric occlusion and then cemented by temporary dental cement. After three months temporary crowns were removed and final porcelain fused to metal crowns were inserted (Figures 2 a-c).

\section{Follow-up for the installed dental implants:}

All patients within the two groups were examined clinically during the first week after implant placement for any signs of pain or infection. Then at intervals of three and six months postoperatively, they were rechecked for implant mobility and osseointegration. On the other hand, a radiographic evaluation through standardized periapical X-rays was performed immediately after implant insertion, then at the $1^{\text {st }}$ month postoperatively, $3^{\text {rd }}$ and at six months to evaluate the bone density around the implants.

Statistical analysis using the appropriate tests was performed using (SPSS software version 20.0) and the collected data were then summarized in tables. 


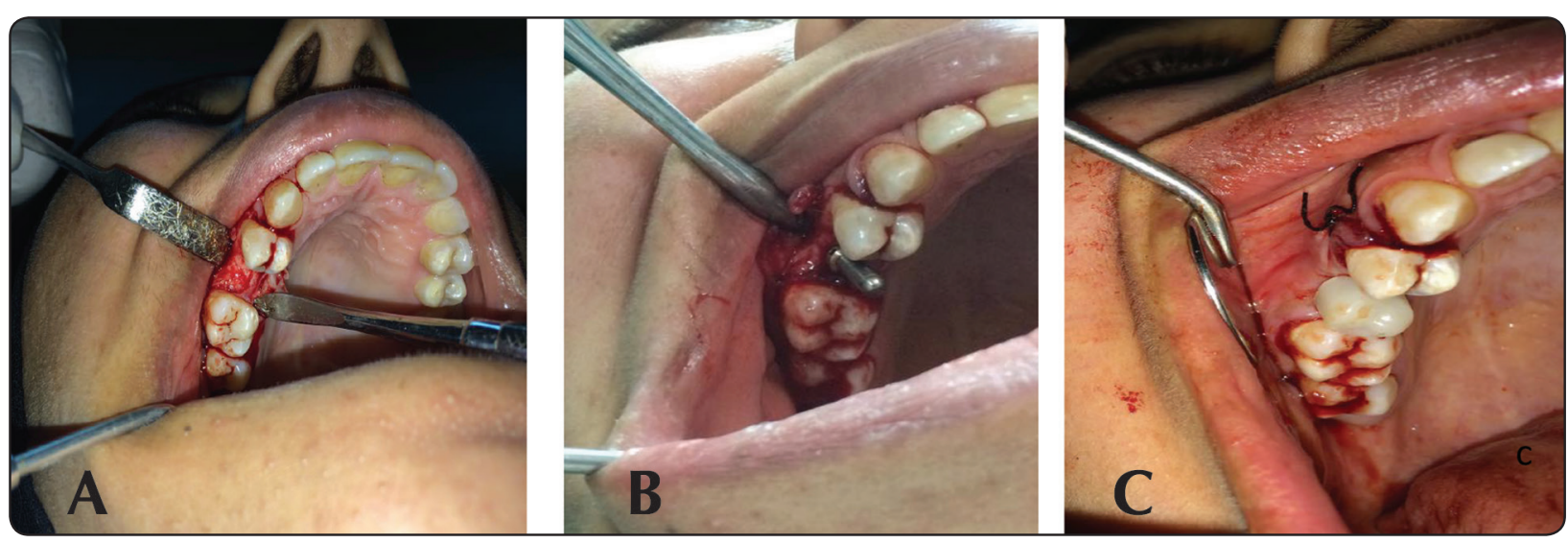

Fig. (2): a) Exposure of bone for implant insertion three months after socket preservation using Alvelac. b) Paralleling pin after drilling of the osteotomy site. c) Immediate loading of inserted implant with a temporary acrylic crown.

\section{RESULTS}

The selected twenty participants were divided equally into two groups; control group and study group each consisted of ten patients. The study group included 8 females and 2 males, their age ranged from 25 to 45 years with a mean of ( 30.83 \pm 7.22 years), while the control group included 6 females and 4 males, their age ranged between 25 to 40 years with a mean of $(32.17 \pm 5.71$ years $)$.

\section{Clinical Results for the preserved sockets:}

Normal color of the oral mucosa, proper healing and adequate closure of the extraction socket were achieved in patients of both groups. No signs of infection were observed in any patient within the two groups throughout the postoperative follow up period.

\section{Radiographic results for the preserved sockets: (figure 3)}

Regarding the alveolar bone width (Table 1), a statistical significant decrease of alveolar bone width in both groups at three months postoperative compared with the bone width at the immediate postoperative period was observed. The percentage of change in alveolar bone width in the control group was (18.87\%) while in the study group, it was much less $(1.04 \%)$. There was a statistically significant difference between the two groups $(\mathrm{t}=8.292, \mathrm{p}=<0.001)$.

TABLE (1) Comparison between the two groups regarding alveolar bone width within the extraction socket:

\begin{tabular}{|c|c|c|c|c|}
\hline Horizontal (width) & Control $(n=10)$ & Study $(n=10)$ & t1 & p1 \\
\hline $\begin{array}{c}\text { Immediately after extraction } \\
\text { Min. }- \text { Max. } \\
\text { Mean } \pm \text { SD. } \\
\text { Median }\end{array}$ & $\begin{array}{c}4.10-7.83 \\
5.70 \pm 1.39 \\
5.74\end{array}$ & $\begin{array}{c}6.65-10.65 \\
8.34 \pm 1.35 \\
8.32\end{array}$ & $3.332 *$ & $0.008 *$ \\
\hline $\begin{array}{l}\text { After } 3 \text { months } \\
\text { Min. - Max. } \\
\text { Mean } \pm \text { SD. } \\
\text { Median }\end{array}$ & $\begin{array}{c}3.13-6.68 \\
4.69 \pm 1.28 \\
4.88\end{array}$ & $\begin{array}{c}6.65-10.50 \\
8.21 \pm 1.29 \\
8.22\end{array}$ & $4.746^{*}$ & $0.001^{*}$ \\
\hline Change after 3 months & $1.01 \pm 0.27$ & $0.13 \pm 0.14$ & $7.012 *$ & $<0.001^{*}$ \\
\hline
\end{tabular}

t: Student t-test, p1: p value for student t-test for comparing between the two groups

* Significance at $\leq 0.05$ 


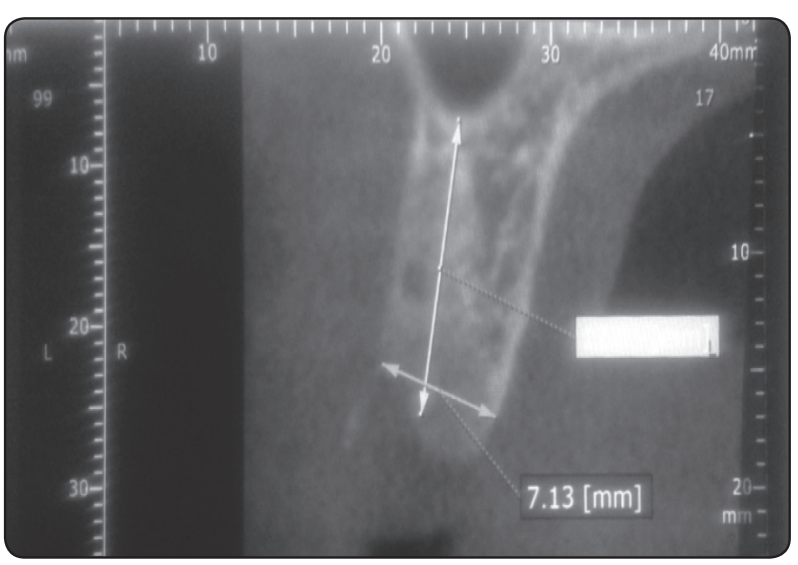

Fig. (3) Alveolar bone dimensions 3 months after extraction at the time of implant insertion
For vertical bone height (Table 2), also a statistically significant decrease of alveolar bone height in both groups at three months post-extraction compared with the bone height at the immediate postoperative period was detected. Furthermore, the percentage of change in alveolar bone height in the control group was $3.68 \%$ while in the study group, it was $0.44 \%$. Comparing those results, a statistically significant difference between the two groups was found $(\mathrm{t}=5.968, \mathrm{p}=<0.001)$.

Finally, for the bone density within the extraction sockets, (Table 3), there was no significant difference between the study and the control groups at three months post-extraction. The percentage of

TABLE (2) Comparison regarding alveolar bone height within the extraction socket among the two groups:

\begin{tabular}{|c|c|c|c|c|}
\hline Vertical (height) & Control $(\mathbf{n}=\mathbf{1 0})$ & Study $(\mathbf{n}=\mathbf{1 0})$ & $\mathbf{t 1}$ & $\mathbf{p 1}$ \\
\hline Immediate after extraction & & & 1.685 & 0.123 \\
Min. - Max. & $15.40-22.38$ & $5.72-20.46$ & & \\
Mean \pm SD. & $19.96 \pm 2.61$ & $15.78 \pm 5.49$ & 18.15 & 0.187 \\
Median & 20.38 & & 1.416 & \\
\hline After 3 months & $14.80-21.71$ & $5.55-20.39$ & & \\
Min. - Max. & $19.23 \pm 2.57$ & $15.70 \pm 5.53$ & & \\
Mean \pm SD. & 19.65 & 18.05 & & \\
Median & $0.74 \pm 0.10$ & $0.08 \pm 0.06$ & $13.971^{*}$ & $<0.001$ \\
\hline
\end{tabular}

t: Student t-test $\quad$ p1: p value for student $t$-test for comparing between the two groups

TABLE (3) Comparison between the two groups according to bone density using cone beam CT.

\begin{tabular}{|c|c|c|c|c|}
\hline Bone density & $($ Control $(n=10$ & $\begin{array}{c}\text { Study } \\
(\mathbf{n}=\mathbf{1 0})\end{array}$ & t1 & p1 \\
\hline $\begin{array}{l}\text { Immediate after extraction } \\
\text {.Min. }- \text { Max } \\
\text {.Mean } \pm \text { SD } \\
\text { Median }\end{array}$ & $\begin{array}{c}513.26-210.58 \\
111.32 \pm 308.58 \\
297.63\end{array}$ & $\begin{array}{c}645.79-312.55 \\
127.60 \pm 397.79 \\
356.16\end{array}$ & 1.291 & 0.226 \\
\hline $\begin{array}{l}\text { After } 3 \text { months } \\
\text {.Min. }- \text { Max } \\
\text {.Mean } \pm \text { SD } \\
\text { Median }\end{array}$ & $\begin{array}{c}646.22-213.75 \\
174.91 \pm 367.06 \\
306.69\end{array}$ & $\begin{array}{c}821.79-325.22 \\
213.54 \pm 547.78 \\
515.35\end{array}$ & 1.604 & 0.140 \\
\hline Change after 3 months & $94.29 \pm-58.48$ & $130.10 \pm-149.99$ & 1.395 & 0.193 \\
\hline
\end{tabular}


change in bone density for the control group was $14.87 \%$, while for the study group was $22.94 \%$ with no statistically significant difference. There was a higher percentage of change in bone density in the study group than in the control group.

\section{Clinical evaluation after implant insertion:}

After implant surgery, all patients experienced slight to mild pain at the surgical site, and five patients (two from the study group and three from the control group) showed mild edema which subsided totally by the seventh post-operative day. All patients continued the follow up period without any signs of infection, gingivitis, or peri-implantitis. Mobility was recorded all over the evaluation period, only one implant showed mobility and thus failed within the control group at six months followup period, none of the other nineteen implants showed any signs of mobility and osseointegration was achieved properly.

\section{Radiographic evaluation after implant insertion}

Standardized periapical radiographs were taken immediately post-operative and at $1^{\text {st }}, 3^{\text {rd }}$ and $6^{\text {th }}$ months follow up period to measure the bone density surrounding the installed dental implants. Radiographic analysis was done using Image $\mathrm{J}$ software (image processing and analysis in Java V. 148 imagej.nih.gov/ij/download/ US).

The mean peri-implant bone density values and standard deviation immediately post- operative, at one month, 3 months and at 6 months were shown in (Table 4). Immediately post-operatively, the mean peri-implant bone density value for the study group was $94.86 \pm 5.43$ while the mean peri-implant bone density value for the control group was $87.70 \pm$ 3.98. This difference in the peri-implant bone density value between the study and control groups was statistically significant $(\mathrm{p}=0.018)$. On the first month after implant insertion, the mean peri-implant bone density value for the study group was

TABLE (4) Comparison between the two groups according to bone density around the installed implants.

\begin{tabular}{|c|c|c|c|c|}
\hline \multicolumn{5}{|c|}{ Bone density } \\
\hline & Immediate postoperative & $1^{\text {st }}$ Month & $3^{\text {rd }}$ Month & $6^{\text {th }}$ Month \\
\hline \multicolumn{5}{|c|}{ Study } \\
\hline Min. - Max. & $85.17-101.78$ & $88.50-102.94$ & $86.67-106.77$ & $92.33-107.02$ \\
\hline Mean \pm SD & $94.86 \pm 5.43$ & $96.54 \pm 5.28$ & $97.74 \pm 6.12$ & $98.70 \pm 5.54$ \\
\hline Median & 97.20 & 97.60 & 98.23 & 99.25 \\
\hline p1 & & $0.006^{*}$ & $0.014^{*}$ & $0.001 *$ \\
\hline \multicolumn{5}{|c|}{ Control } \\
\hline Min. - Max. & $81.66-91.97$ & $80.33-92.50$ & $85.96-103.72$ & $93.82-105.0$ \\
\hline Mean \pm SD & $87.70 \pm 3.98$ & $88.28 \pm 4.49$ & $95.95 \pm 5.75$ & $98.84 \pm 3.68$ \\
\hline Median & 88.95 & 89.46 & 97.55 & 98.95 \\
\hline p1 & & 0.478 & $0.020 *$ & $0.003^{*}$ \\
\hline $\mathbf{T}$ & $2.747 *$ & $2.821^{*}$ & 0.251 & 0.184 \\
\hline $\mathbf{P}$ & $0.018^{*}$ & $0.015^{*}$ & 0.806 & 0.857 \\
\hline
\end{tabular}

t: Student t-test

p1: p value for Pairedt-test for comparing between Immediate postoperative with each other periods in each group

*: Statistically significant at $p \leq 0.05$ 
$96.54 \pm 5.28$ while the mean peri-implant bone density value for the control group was $88.28 \pm 4.49$. This difference in peri-implant bone density value between the study and control groups was also statistically significant. $(p=0.015)$. On the third month, the mean peri-implant bone density value for the study group was $97.74 \pm 6.12$ while the mean periimplant bone density value for the control group was 95.95 \pm 5.75 . This difference in peri-implant bone density value between the study and control groups was statistically not significant. $(p=0.806)$. On the sixth month, the mean peri-implant bone density value for the study group was $98.70 \pm 5.54$ while the mean peri-implant bone density value for the control group was $98.84 \pm 3.68$. This difference in peri-implant bone density value between the study and control groups was statistically not significant. $(\mathrm{p}=0.857)$.

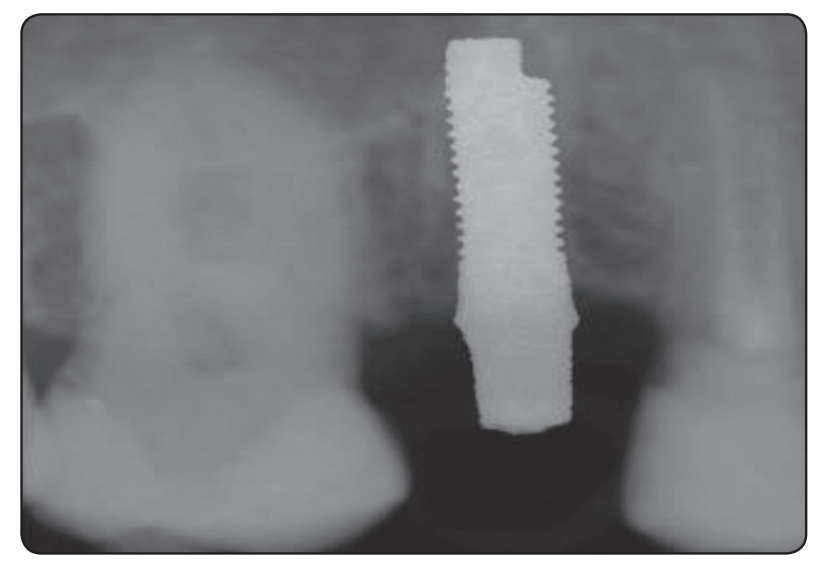

Fig. (4) Periapical radiograph showing the installed dental implant within the preserved sockets

\section{DISCUSSION}

The rationale for alveolar ridge preservation relies on the knowledge that the alveolar ridge resorption is an unavoidable sequela of tooth loss. ${ }^{(13)}$ Its goal is to prevent the loss of $40 \%-60 \%$ of ridge height and width commonly seen after extractions. ${ }^{(14)}$

Preservation of socket is driven by the desire to minimize the need for future more invasive ridge augmentation procedures. Moreover, it also facilitates successful implant and conventional prosthetic treatment. Extraction site grafting often facilitates the best possible functional and aesthetic results. It is axiomatic therefore that socket preservation should be the treatment of choice to prepare the remaining alveolar ridge for conventional or fixture supported restorations..$^{(15,16)}$

The success of osseointegrated dental implants depends on whether there is a sufficient volume of healthy bone at the recipient site at the time of implant placement. The placement of an implant at a site with a thin crestal ridge (e.g., post extraction ridge) could result in a significant buccal dehiscence. Thus, it seems prudent to prevent alveolar ridge destruction and make efforts to preserve it during extraction procedures. ${ }^{(17)}$

Alveolar ridge preservation is a relatively new surgical procedure aimed at retaining maximum bone and soft tissue after a tooth has been removed. By maintaining the original ridge morphology, there will be a minimal need for augmentation procedures thereby allowing the resultant restoration to be placed in an aesthetically and functionally ideal position. ${ }^{(18)}$

Simion and coworkers $(2001)^{(19)}$ have suggested that success rates are satisfactory when placing implants in previously grafted bone. In a retrospective study of 607 titanium plasma sprayed implants placed in regenerated bone (with DFDBA), 97.2\% of maxilla implants and $97.4 \%$ of mandible implants were successful for an average of 11 years.

This study was designed to evaluate the use of Alvelac $^{\mathrm{TM}}$ as a socket preservative material with subsequent placement of immediately loaded dental implants. It was conducted on twenty patients divided into two equal groups (study group and control group) who were indicated for extraction of posterior maxillary teeth. In the study group, the bioscaffold Alvelac ${ }^{\mathrm{TM}}$ was inserted into the empty socket after extraction and was supported by 3-0 silk with figure of eight sutures. On the other hand, 
in the control group extraction was done without introducing any material and the wound was sutured. Three months post-extraction, immediately loaded implants were inserted in both groups.

Several studies have evaluated the effect of PLGA with different grafting materials. ${ }^{(20)}$ Defects that were treated with $\mathrm{Mg} /$ PLGA scaffolds had an improved bone height preservation compared with empty defects at both 8 and 16 weeks post-surgery. This effect compares well with other bone-grafting materials (including polymers) that have been successfully used for socket preservation..$^{(20,21)}$

According to Fan $(2008)^{(22)}$, a bio-scaffold, placed immediately after tooth extraction, helps and allows for bone to grow into it and prevents the socket from collapsing. The results of the present study are in accordance with Fan's results regarding an increase in the bone density and protection of the height and width of the alveolar bone after tooth extraction.

In a study by Serino et al $(2013)^{(23)}$, the use of a bioabsorbable synthetic sponge of polylactidepolyglycolide acid was evaluated. The results of this study indicate that alveolar bone resorption following tooth extraction may be prevented or reduced by the use of a bioabsorbable synthetic sponge of polylactide-polyglycolide acid. The quality of bone formed seemed to be optimal for dental implant insertion. The material is similar in content to Bioscaffold Alvelac ${ }^{\mathrm{TM}}$ used in the present study.

A similar osteoconductive scaffold, OsteoScaf, was used by Araujo et al (2015). ${ }^{(24)}$ The results obtained from CBCT measurements have clearly shown that OsteoScaf protection impaired the expected bone lost during the post extraction remodeling of the alveolar bone ridge at 120 days post extraction .This result is also in agreement with the results of the current study.

As for alveolar bone width and height, the current work reveals statistically significant difference between the two groups, regarding the percent of change three months post-extraction and at the time the implants were inserted. This could be attributed to the effect of socket preservation on increasing the bone quantity and preserving the alveolar bone dimensions for subsequent implant insertion.

Three months following the extraction and socketpreservation, implants were inserted and immediately loaded. This work proposed that the increase in bone density around the implants is indicative of its success. The current work reveals statistically significant difference in bone density between the two groups, immediately post-operative and at the first month after implant insertion. This could be attributed to the effect of socket preservation on increasing the bone quality. However, at the time of three and six months after implants were inserted, there was no statistically significant difference between the two groups.Both groups showed increase in peri-implant bone density from the immediate postoperative period to the end of the 6 months of the evaluation period which indicates osseointegration of all implants.

\section{CONCLUSION}

Within the context of this study, the following conclusions can be elaborated; insertion of the bioscaffold Alvelac ${ }^{\mathrm{TM}}$ material in the socket immediately after tooth extraction allows it to act as a scaffold for bone deposition and it assists the natural healing process. Furthermore, treating the socket with Bioscaffold results in natural healing within the given time frame with better bone quality.It is clear that this material allows preservation of the dimensional measures of alveolar bone after tooth extraction. Finally, the material is believed to assist in increasing the success rate of the immediately loaded dental implants.

\section{REFERENCES}

1. Keith JD Jr, Salama MA. Ridge preservation and augmentation using regenerative materials to enhance implant predictability and esthetics. Compend Contin Educ Dent. 2007;28(11):614-21. 
2. Norton MR. A short-term clinical evaluation of immediately restored maxillary TiOblast single-tooth implants. Intl J Oral Maxillofacial Imp.2004; 19(2):274-81.

3. Araújo M1, Linder E, Lindhe J. Effect of a xenograft on early bone formation in extraction sockets: an experimental study in dog.Clin Oral Implants Res. 2009;20(1):1-6.

4. Mecall RA, Rosenfeld AL. Influence of residual ridge resorption patterns on implant fixture placement and tooth position. Int J Periodontics Restorative Dent. 1991;11(1):8-23.

5. Sevor JJ, Meffert R. Placement of implants into fresh extraction sites using a resorbable collagen membrane: case reports.Pract Periodontics Aesthet Dent. 1992;4(3):35-41.

6. Grunder U, Polizzi G, Goené R, Hatano N, Henry P, Jackson WJ et al. A 3-year prospective multicenter follow-up report on the immediate and delayed-immediate placement of implants. Int J Oral Maxillofac Implants. 1999;14(2):210-6.

7. Nimigean VR1, Nimigean V, Bencze MA, Dimcevici-Poesina N, Cergan R, Moraru S. Alveolar bone dehiscences and fenestrations: an anatomical study and review.Rom J Morphol Embryol. 2009; 50(3):391-7.

8. Kutkut A, Andreana S, Kim HL, Monaco E Jr. Extraction socket preservation graft before implant placement with calcium sulfate hemihydrate and platelet-richplasma: a clinical and histomorphometric study in humans. J Periodontol. 2012;83(4):401-9.

9. Jackson BJ, Morcos I. Socket grafting: a predictable technique for site preservation.J Oral Implantol. 2007;33(6):353-64.

10. Atieh MA, Alsabeeha NH, Payne AG, Duncan W, Faggion CM, Esposito M. Interventions for replacing missing teeth: alveolar ridge preservation techniques for dental implant site develop- ment. Cochrane Database Syst Rev. 2015; 28; 5:CD010176.

11. Arenaz-Búa J1, Luaces-Rey R, Sironvalle-Soliva S, Otero-Rico A, Charro-Huerga E, PatiñoSeijas B et al. A comparative study of plateletrich plasma, hydroxyapatite, demineralized bone matrix and autologous bone to promote bone regeneration after mandibular impacted third molar extraction. Med Oral Patol Oral Cir Bucal. 2010;15(3):e483-9.

12. Sager M, Darwish S, Melek L. The effect of bioscaffold ALVELAC ${ }^{\mathrm{TM}}$ in preservation of alveolar bone after extraction of teeth (clinical and radiographic study). Alexandria Dental Journal. 2015; 40:22-6.

13. Wang HL, Kiyonobu K, Neiva RF. Socket augmentation: rationale and technique. Implant dentistry 2004; 13: 286-96.

14. Ashman A. Post extraction ridge preservation using synthetic alloplast. Implant Dent 2000; 9: 168-76

15. Fickl S, Zuhr O, Wachtel H, Bolz W, Huerzeler M. Hard tissue alterations after socket preservation: an experimental study in the beagle dog. Clin Oral Implant Res 2008; 19: 1111-8.

16. Sethi A, Kaus T. Maxillary ridge expansion with simultaneous implant placement: a 5-year results of an ongoing clinical study. Int J Oral Maxillofac Implants 2000; 15: 491-9.

17. Irinakis T. Rationale for socket preservation after extraction of single rooted tooth when planning for future implant placement .J of Can Dental Assoc 2006; 72: 917-22.

18. Darby I, Chen ST, Buser D. Ridge preservation techniques for implant therapy. Int J Oral Maxillofac Implants 2009; 24 :260-71.

19. Simion M, Jovanovic SA, Tinti C, Benfenati SP. Long-term evaluation of osseointegrated implants inserted at the time or after vertical ridge 
augmentation. A retrospective study on $123 \mathrm{im}-$ plants with 1-5 year follow-up. Clin Oral Implants Res 2001; 12: 35-45.

20. Dobrovolskaia MA, Aggarwal P, Hall JB, McNeil SE. Preclinical studies tounderstand nanoparticle interaction withthe immune system and its potential effects on nanoparticle biodistribution. Molecular pharmaceutics 2008; 5: 487-95.

21. Serino G, Rao W, Iezzi G, Piattelli A. Polylactide and polyglycolide sponge used in human extraction sockets: bone formation following 3 months after its application. Clin Oral Implant Res 2008;19(1): 16-31.
22. Fan V. Sacaffold to aid tooth implants. NUH 2008;26: 1-2.

23. Serino G, Biancu S, Iezzi G, Piattelli A. Ridgepreservation following tooth extraction using apolylactide and polyglycolide sponge as space filler:a clinical and histological study in humans. Clin Oral Implant Res 2003; 14: 651-8.

24. Araujo AC, Mendes VC, Junior OF, Carvalho PS, Guan L, Davies JE. Investigation of a NovelPLGA/CaP Scaffold in the Healing of ToothExtraction Sockets to Alveolar Bone Preservation inHumans. Clin Implant Dent Relat Res 2015; 5: 1-12. 